\title{
Development of a wireless sensor network based smart multiple ambient conditions sensing system for the rearing process of eri silkworm
}

\author{
Arnob Doloi ${ }^{1^{*}}$, Nairit Barkataki ${ }^{2}$, Monimala Saikia $^{3}$ and Debashis Saikia ${ }^{2}$ \\ PG Student, Department of Instrumentation and USIC, Gauhati University, Assam, India ${ }^{1}$ \\ Assistant Professor, Department of Instrumentation and USIC, Gauhati University, Assam, India ${ }^{2}$ \\ Assistant Professor, Department of Sericulture, Assam Agricultural University, Jorhat, Assam, India ${ }^{3}$ \\ Received: 11-January-2019; Revised: 18-March-2019; Accepted: 22-March-2019 \\ (C)2019 Arnob Doloi et al. This is an open access article distributed under the Creative Commons Attribution (CC BY) License, \\ which permits unrestricted use, distribution, and reproduction in any medium, provided the original work is properly cited.
}

\begin{abstract}
Assam has a strong contribution in the world silk production. Several rural families of this region are engaged in this activity. Socioeconomic development of this region is also dependent on these activities. This paper presents a wireless sensor network-based instrumentation to record the process conditions of the rearing process of eri silkworm, which can further help to optimize the rearing process. For this purpose, temperature, relative humidity, light intensity takes as major process parameters on which the rearing process depends. These parameters are recorded using sensor $B M E 280$ for temperature \& relative humidity and $\mathrm{BH} 1750$ for light intensity which is interfaced with an ATmega328/P microcontroller. This works as a sensor node and three sensor nodes are required for complete monitoring of the rearing process. Wireless sensor network is utilized for interconnecting each sensor node through a master node which obeys star topology. The system is then tested in the laboratory and compared with the standard equipment. The system is installed in the rearing process for data collection. The collected data are further analyzed for its daily variations.
\end{abstract}

\section{Keywords}

Wireless sensor network, Rearing process, Eri silkworm, Sensor node.

\section{Introduction}

Sericulture is an agro based cottage industry of Assam, comprising of both mulberry and nonmulberry or anya silkworm culture. Silk production has the potential to make a significant contribution to the economy of many countries where there is a large labour force, low-cost of production and a willingness to adopt new technologies [1]. Assam is the only place in the world where all of the four commercial silkworm varieties viz., mulberry, eri, muga and tasar silkworm is produced. Non-mulberry silk in general, muga and eri silk in particular, have closely associated with the rituals and traditions of Assam, and thus silk production and its uses have been an important household activity leading to economic development of a large section of rural people. Out of four sericulture products, eri holds the first position in terms of production and generation of employment in Assam, though in Indian market mulberry occupies the first position and followed by the eri.

\footnotetext{
*Author for correspondence
}

Assam is the highest producer of eri silk in the country with 3143 MT raw silk production [2].

A total of 5,52,063 families are engaged in production of eri silk [3]. Eri culture has always been a subsidiary occupation of the rural folk of IndoMongoloid and Tibeto-Burman races of the Brahmaputra valley. Communities like the Misings, Kacharis, Bodos, Mikirs, Rabhas, Karbis, Garos practice this culture during their leisure time and it helps to improve their economic condition. Though eri culture is practiced in almost all the districts of Assam, it is highly concentrated in the districts of Karbi Anglong, North Cachar Hills, North Lakhimpur, Demaji, Barpeta, Kokrajhar, Sibsagar, Darrang etc.

The word 'Eri' derived from the word 'era' which means castor. The eri silkworm, Samia ricini Donovan (Lepidoptera: Satumiidae) is a holometabolous, polyphagous and multivoltine insect. It is one of the most exploited, domesticated and commercialized non-mulberry silkworms. It is very common in the Northeast region of India which 
can be reared indoor all the year round feeding on different varieties of plants. It feeds on over 29 species of host plants [4]. The important food plants of eri silkworm are castor (.Ricinuscommunis L.), barpat (Ailanthus grandis Prain) kesseru (Heteropanax Fragrans Seem), barkessera (Ailanthusexcelsa Roxb.), tapioca (.Manihot esculanta Crantz), and payam (Evodia flaxinifolia Hook). Among these, castor is the most preferred host plant [5-8] which has been accepted for commercial rearing since time immemorial. Though eri culture has been surviving for a long period of time it is not growing at a faster rate due to the lack of capital of the eri rearers and that of the common weavers that prohibits technological invention and innovation.

In Assam eri culture is done in a traditional way. The farmers are not so much familiar with the use of modern scientific techniques and advanced technologies in the management of the early host plant garden, silkworm rearing, spinning and weaving. With the advent of new technologies and increasing competition in the global market, this traditional way of eri culture proved to be less profitable to the farmers.

For speeding up the silk production and quality, there is an urgent need to develop advanced technology suitable for tropical sericulture. The cost of the technology will play a vital role because economic status of the technology users is not up to the mark in this region. So, the developed technology must satisfy both the issues i.e. cost and agro climatic conditions [9].

The productivity and quality of cocoon, however, depend upon quality food supply, favourable environmental conditions and utmost hygienic condition [10-13]. The ambient temperature during rearing affects larval growth, survival rate, cocoon parameters and silk quality. The ideal range of temperature for the growth of eri silkworm is from $20^{\circ} \mathrm{C}$ to $40^{\circ} \mathrm{C}$. However, the increase in temperature beyond $35^{\circ} \mathrm{C}$ causes less spinning, mortality of larva and pupae and poor moth emergence and sterility at adult stage $[14,15]$. The low humidity influenced the survival rates of insects (Hamilton, 1950). In eri silkworm the optimum temperature for growth of young stage is about $26-28^{\circ} \mathrm{C}$ with a relative humidity of $85-90 \%$ and at later stage $24-26^{\circ} \mathrm{C}$, with $70-80 \%$ [16]. However, the literature regarding atmospheric pressure and light intensity is scanty.
For precision agriculture, the farmers are required greater amount of expertise in farming and agricultural practices. However, by implementing wireless sensor network (WSN) multiple problems such as irrigation, harvesting, planting, disease control etc. can be solved. Another benefit of WSN is its ease of installing sensor nodes in the system which is generally plug and play. It will benefit the user, i.e. the user can put the sensor node whenever and wherever it will be required [17].

In oil and gas (O\&G) industry several critical challenges were solved by using WSN based monitoring system. This type of reliability WSN based monitoring and control system helps $O \& G$ industry to provide better human safety and maintenance of their property [18].

In the present study, a low cost WSN network has been used to monitor temperature, humidity, atmospheric pressure and light intensity which will further benefit the fraternity related to sericulture farming.

\section{Conventional process of monitoring environmental conditions}

The ambient temperature, relative humidity, atmospheric pressure and light intensity are crucial atmospheric parameters relevant to the life parameters of eri silk worm (Samia recini Donovan) in the rearing process. Conventionally these parameters are monitored by the following means as given in Table 1.

Table 1 Environmental parameter monitoring instrument

\begin{tabular}{ll}
\hline Parameter & Instrument \\
\hline Temperature & Mercury in glass thermometer \\
Humidity & Dry and wet bulb hygrometer \\
Atmospheric pressure & Barometer \\
Light intensity & Lux meter \\
\hline
\end{tabular}

In $21^{\text {st }}$ century electronic instruments are widely used over traditional instruments. This is because of their better resolution, much higher accuracy, repeatability and relatively low power consumption. These instruments are free from observational error, like parallax and approximation. These can be operated without the presence of human instructor, as most of them are automatic. The measured signal can easily be transmitted over long distance. Many measurements can be performed simultaneously or rapidly. 


\section{Objective}

Temperature, humidity and light intensity in rearing houses are measured with the help of thermohygrometer and digital Lux meter respectively. Generally, these parameters are measured 2-3 times daily. It is difficult to measure temperature, humidity or light intensity of the rearing room in every second or minute. Most of the eri rearers of this region are economically backward. So, a low-cost intelligent system is indeed a necessity which will lead to accurate measurement of the environmental conditions. The sericulture authority can use the system to monitor the causes of failure \& success of the crop and accordingly they can give support to the farmers regarding the management practices. It can bring a new hope in the eri silk industry of Assam. Therefore, the present investigation to develop a smart multiple atmospheric parameter sensing system and monitor the environmental condition in the eri silkworm rearing house was carried out with the following objectives:

1. To develop the sensor node of the instrument

2. To develop the network for communication among each node.

3. To test the developed instrument in the laboratory environment.

4. To install the developed instrument in the rearing room of eri silkworm.

5. To monitor and collect the multiple atmospheric parameters during rearing of eri silkworm.

6. To analyse the collected data.

\section{Development of sensor nodes}

4.1Temperature, humidity, atmospheric pressure sensor

The BME 280 is an integrated environmental sensor developed specifically for mobile application where size and low power consumption are key design constraints. The unit combines individual high linearity and high accuracy sensors for temperature, pressure and humidity. The BME 280 designed for low current consumption (3.6 $\mu \mathrm{A} @ 1 \mathrm{~Hz})$. The humidity sensor provides an extremely fast response time of $1 \mathrm{~s}$ for fast context aware applications and high overall accuracy over a wide temperature range. The pressure sensor is an absolute barometric pressure sensor with extremely high accuracy, resolution and low noise $0.2 \mathrm{~Pa}$. The integrated temperature sensor has been optimized for lowest noise and highest resolution.

The sensor provides both serial peripheral interface (SPI) and inter-IC $\left(\mathrm{I}^{2} \mathrm{C}\right)$ interfaces and can operate between $1.71 \mathrm{~V}$ to $3.6 \mathrm{~V}$ of the voltage supply. 52
Measurement can be triggered by the host or performed in regular intervals. When the sensor is disabled, current consumptions drop to $0.1 \mu \mathrm{A}$ [19]. The measurement flow of BME 280 given in Figure 1 .

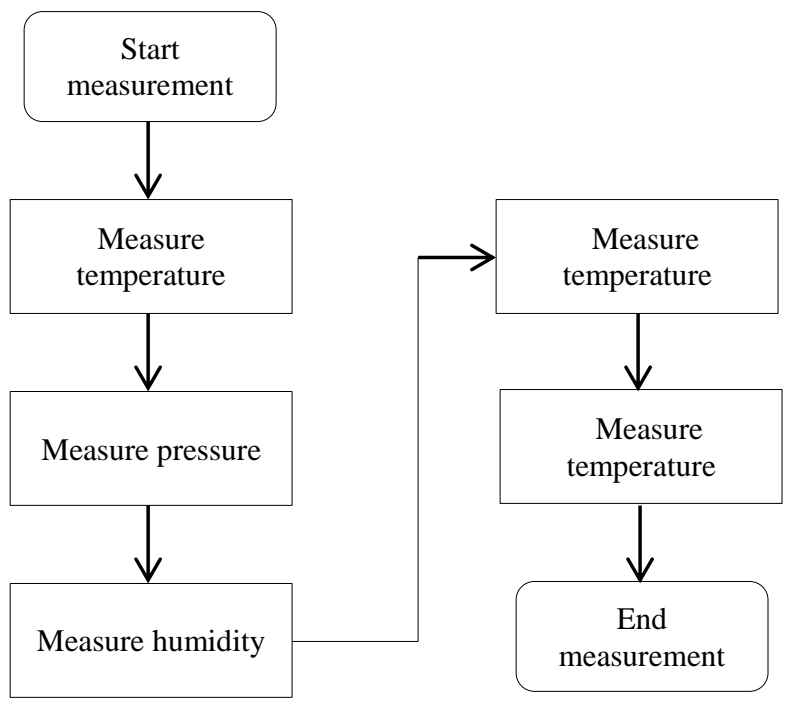

Figure 1 Measurement flow of BME280

\subsection{Light intensity sensor}

BH1750 Light intensity sensor IC: BH1750 is a digital ambient light sensor IC. Photo diode is used as a light intensity detector in this IC. The spectral response of the IC is approximately similar to human eye response. With typical current draw of only 120 $\mu \mathrm{A}$, the BH1750 has been often ideally suited for low power battery operated system such as mobile phone, digital camera, PDA, note PC, etc. [20].

\subsection{Sensor node development}

The sensors are interfaced with an ATmega328/P microcontroller [21]. The algorithm of the firmware embedded in the microcontroller associated with the sensor node is given below:

- Step 1: Configure serial port

- Step 2: Read serial port

- Step 3: Check the incoming signature.

- Step 4: If the signature matched, read the sensor. Otherwise, go to Step 2

- Step 5: Read the register of sensor_1 containing temperature data

- Read register 0xFA for temperature MSB

- Read register 0xFB for temperature LSB

- Step 6: Send data to serial port with signature

- Step 7: Read the register of sensor_1 containing humidity data

- Read register 0xFD humidity MSB

- Read register 0xFE humidity LSB 
- Step 8: Send data to serial port with signature

- Step 9: Read the register of sensor_1 containing pressure data

- Read register 0xF8 pressure LSB

- Read register 0xF7 pressure MSB

- Step 10: Send data to serial port with signature

- Step 11: Read the register of sensor_1 containing altitude data

- Step 12: Send data to serial port with signature

- Step 13: Read the register of sensor_2 containing light intensity

- Step 14: Send data to serial port with signature

- Step 15: Initialize the memory location containing the received signature

- Step 16: Repeat step 2

The program for the sensor node has been developed in C. The developed sensor node is shown in Figure 2 .

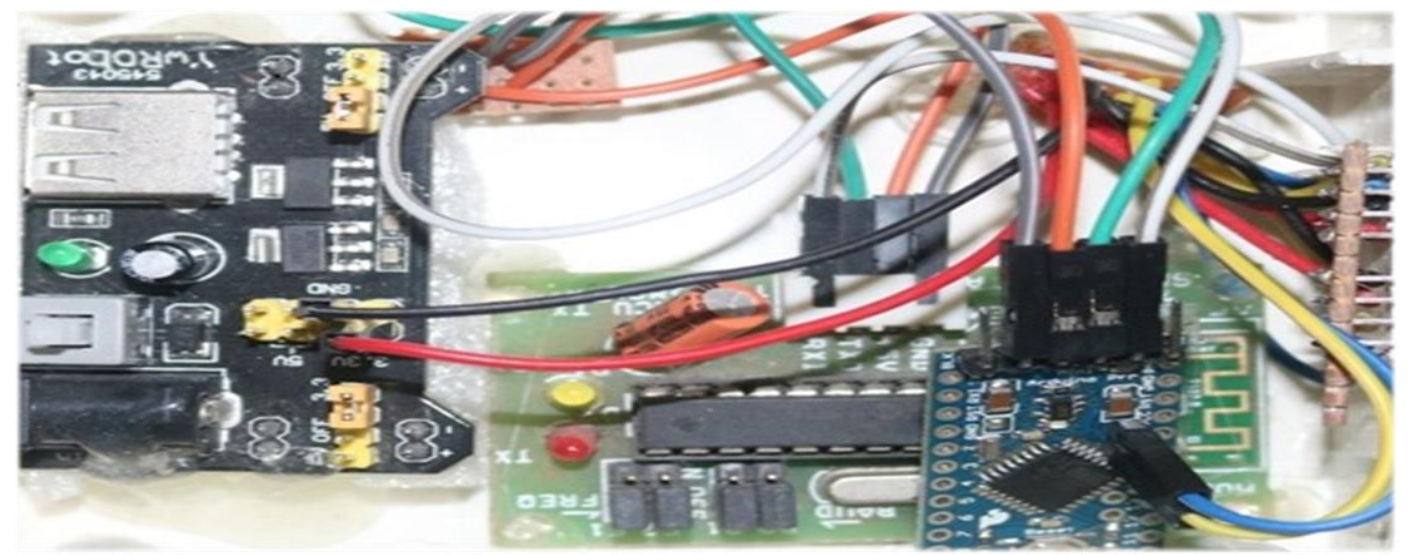

Figure 1 View of developed sensor node

\section{Development of sensor network and master node}

A wireless network has been developed for interconnection among the sensor nodes with the master node. For this purpose, RF modem has been used. The CC2500 RF modem is a transceiver module which provides easy to use RF communication at $2.4 \mathrm{GHz}$. It can be used to transmit and receive data at multiple baud rates from any CMOS/TTL source. This module is a direct replacement for serial communication. It works in half duplex mode i.e. it provides communication in both directions, but only one direction at same time. The switching from receiver to transmitter mode is done automatically [22].

The developed wireless network follows star network topology. In star topology, each network host is connected to a central hub with a point-to-point connection. The central hub is the master and peripherals are clients. The star topology is considered as the easiest topology to design and implement. An advantage of the star topology is the simplicity of adding additional nodes. The primary disadvantage of this topology is that the hub represents a single point of failure [23]. Flowchart representation of the firmware is shown in Figure 3.

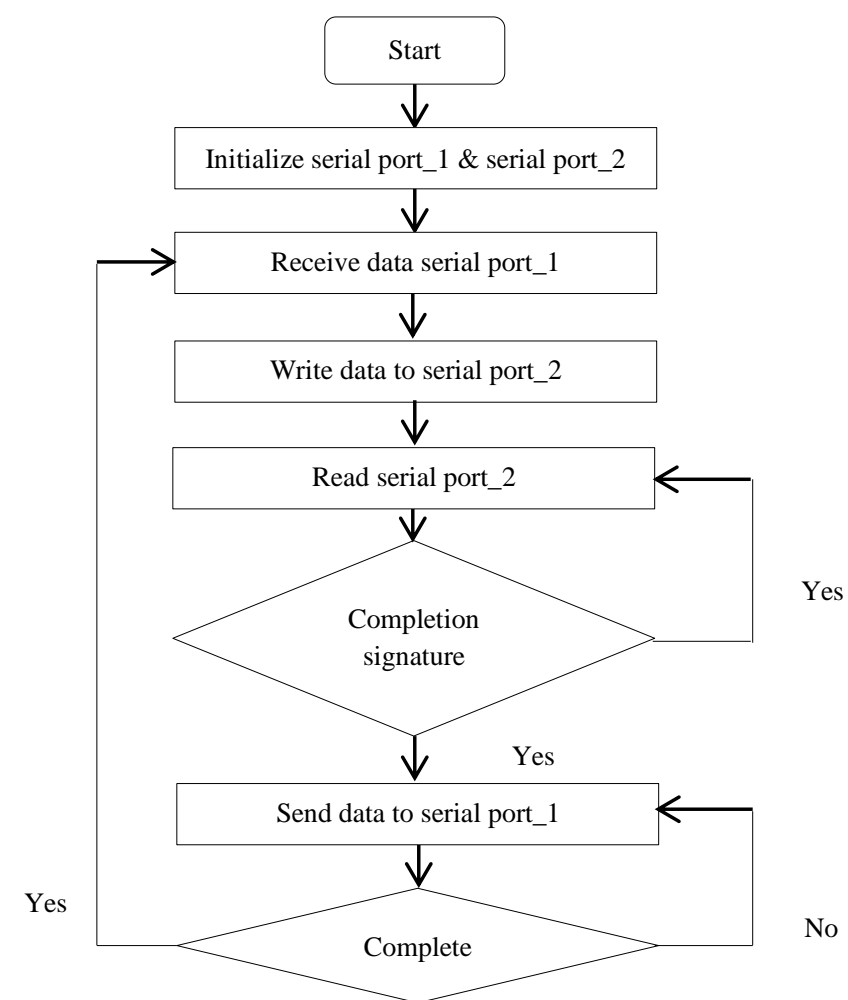

Figure 3 Flowchart of the firmware embedded in the microcontroller 
The developed master i.e. the host with RF module is shown in the Figure 4. The pictorial representation of networking of developed instrument is shown in Figure 5.

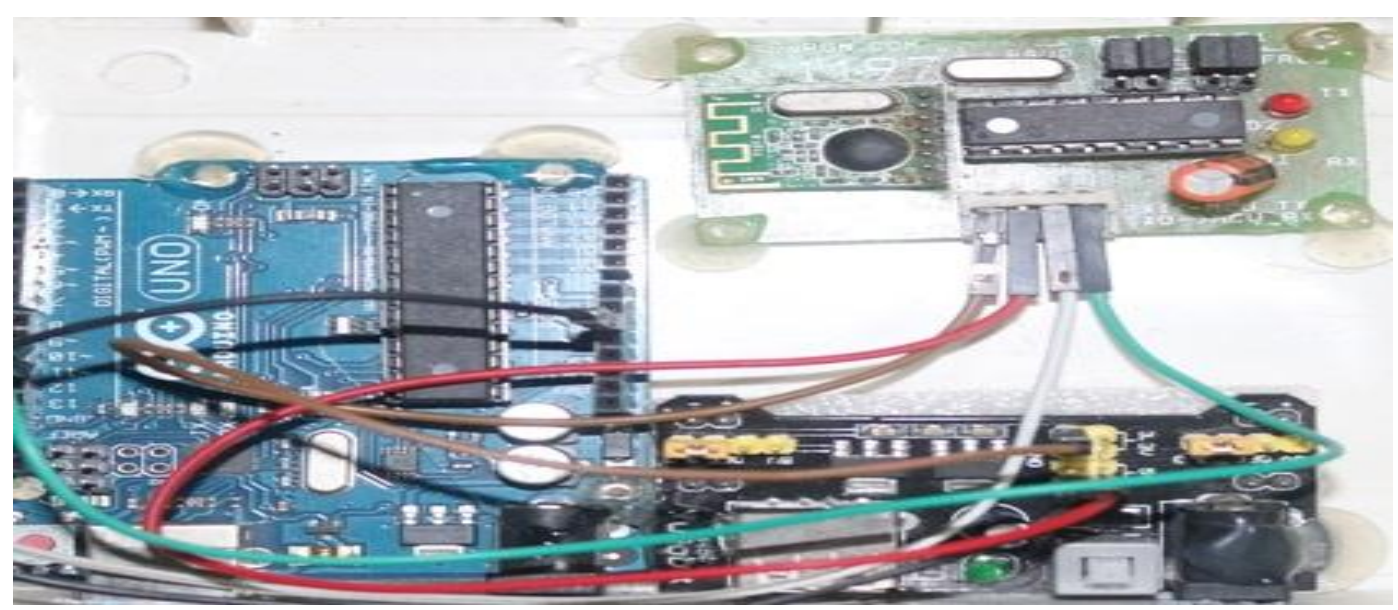

Figure 4 View of developed master node

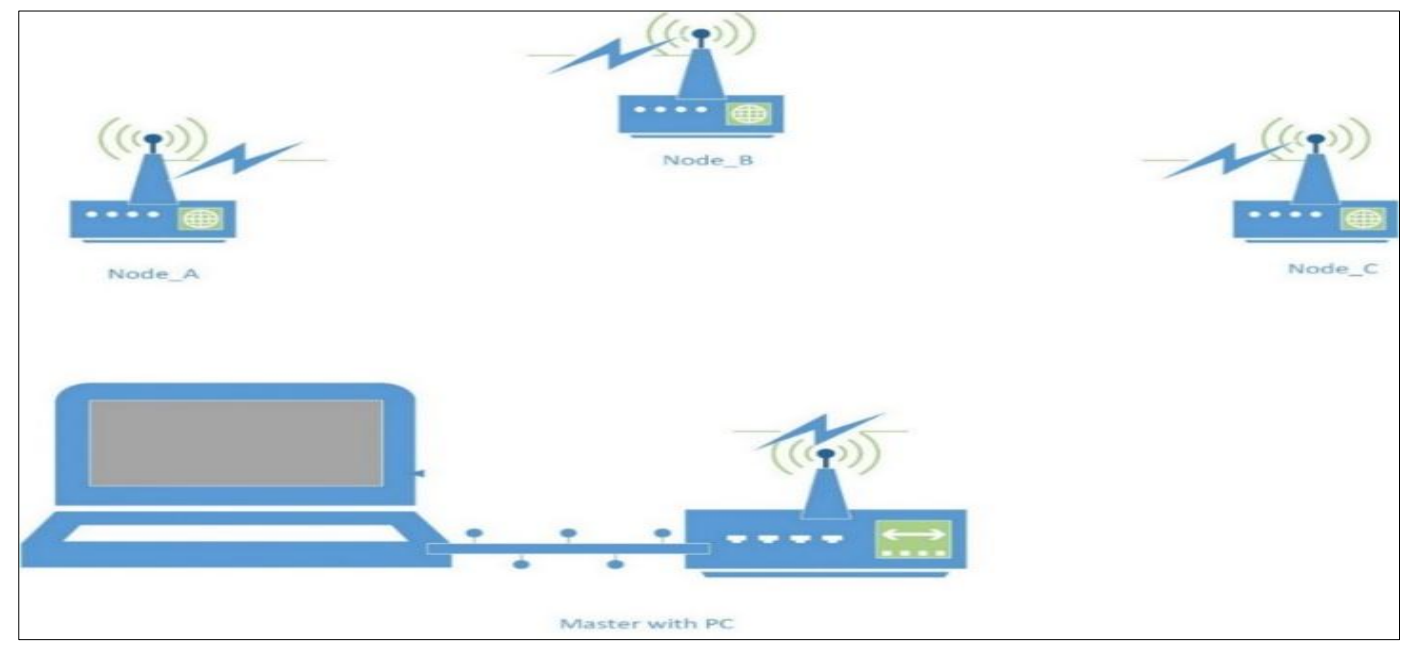

Figure 5 Pictorial representation of networking of developed system

A graphical user interface (GUI) and data acquisition system has been developed in NI LabVIEW for collecting the temperature, relative humidity, atmospheric pressure, altitude and light intensity from the sensor nodes (shown in Figure 6). The LabVIEW algorithm of the proposed system is given below.

- Step 1: Select COM port in VISA configure serial port vi

- Step 2: Send command to the write buffer of VISA write vi

- Step 3: In VISA read vi read buffer is connect to the scan value vi

- Step 4: Scan the string if the value matched then filtered out
- Step 5: Filtered value convert to number by using decimal string to number vi

- Step 6: The number is put into an array in build an array block

- Step 7: The output of build array is connected to the array to spread sheet string vi

- Step 8: Date and time block and spread sheet string output connect to concatenate string vi

- Step 9: In write character to file vi output of the string is connect

- Step 10: Data are save in a .txt file as defined in write character to file vi 


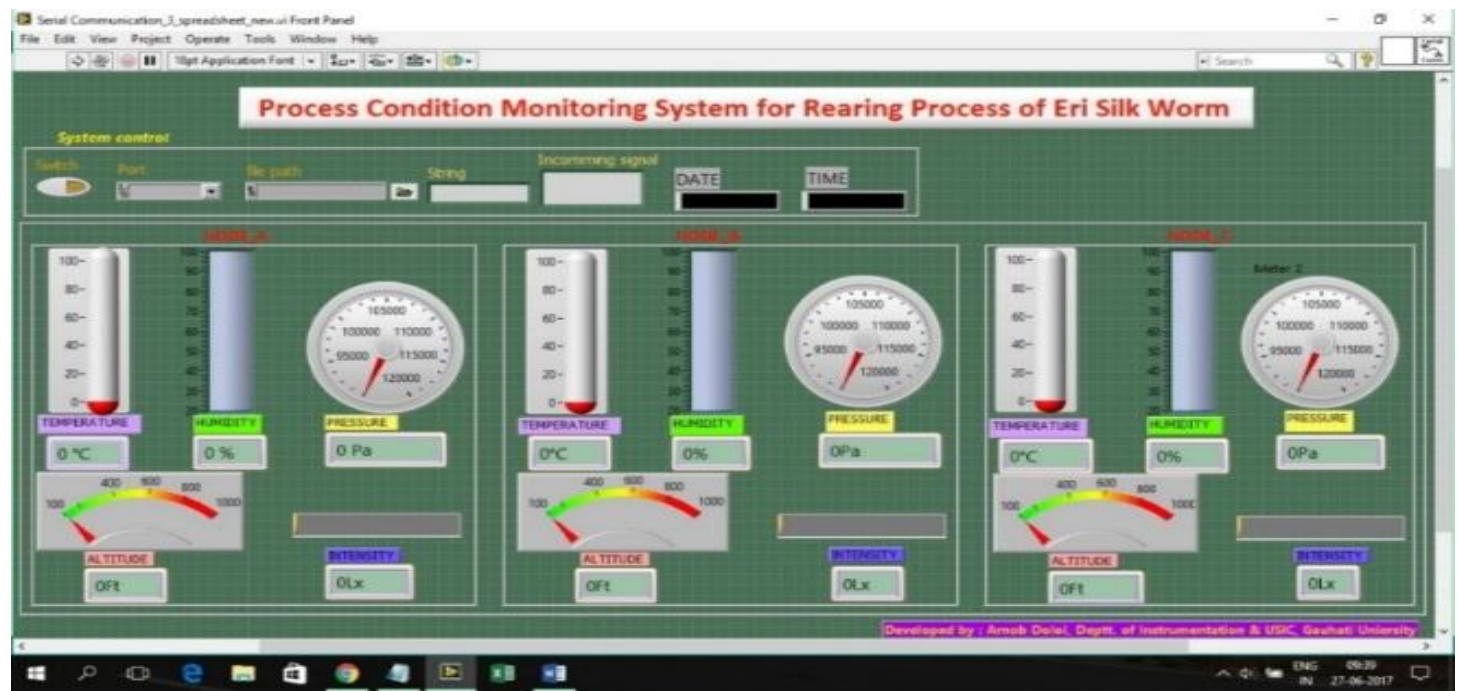

Figure 6 Screenshot of portion of developed LabVIEW program

Since the sensors are pre calibrated hence calibration of the developed system is not done.

\section{Laboratory testing}

The developed system had been tested in the laboratory environment, at Department of Instrumentation \& USIC, Gauhati University. During the period of testing, laboratory temperature kept constant with the help of an air conditioner. The standard laboratory conditions have been recorded by means of the instrument as given in Table 2. Their recorded values are also depicted in the stated table.
Table 2 The standard laboratory conditions

\begin{tabular}{lll}
\hline Instrument & Parameter & Value \\
\hline $\begin{array}{l}\text { Mercury in glass } \\
\text { thermometer }\end{array}$ & Temperature & $23^{\circ} \mathrm{C}$ \\
\hline $\begin{array}{l}\text { Dry and wet bulb } \\
\text { thermometer }\end{array}$ & Relative humidity & $73 \% \mathrm{RH}$ \\
\hline Lux meter & Light intensity & $185 \mathrm{Lux}$ \\
\hline
\end{tabular}

The data recorded by the developed system are graphically represented in the Figure 7 , Figure 8 , and Figure 9 for a single day. The results show that the variations are very few of the parameters among the nodes. Again, it has been seen that the collected data are similar to the standard data as given in Table 2.

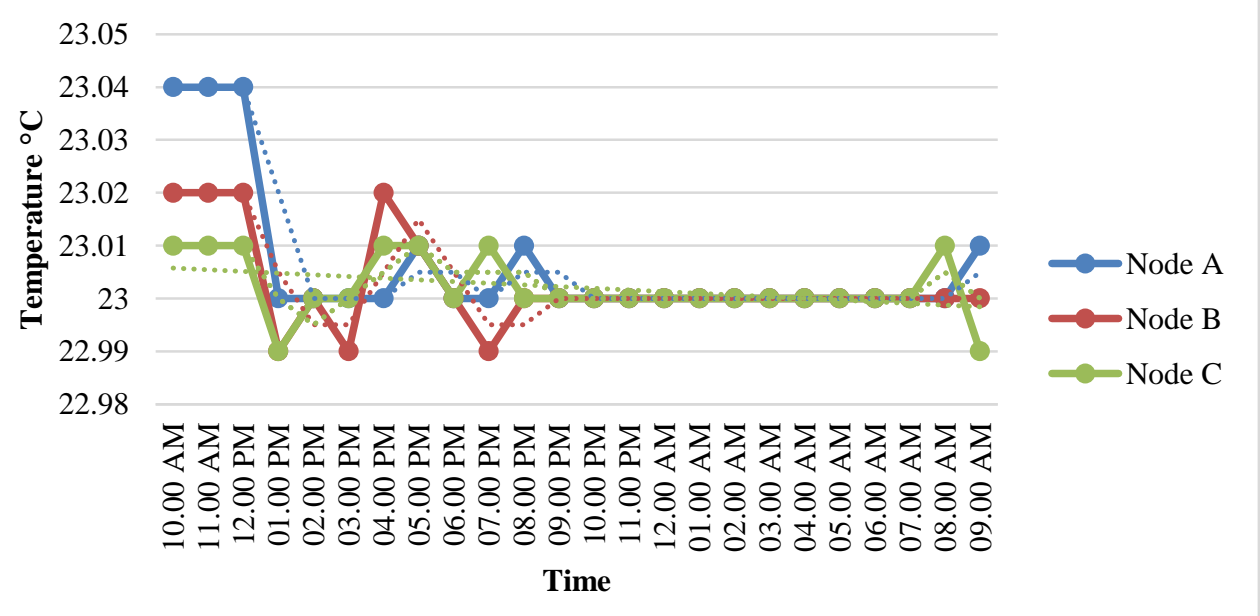

Figure 7 Variation of temperature in laboratory environment 
Arnob Doloi et al.

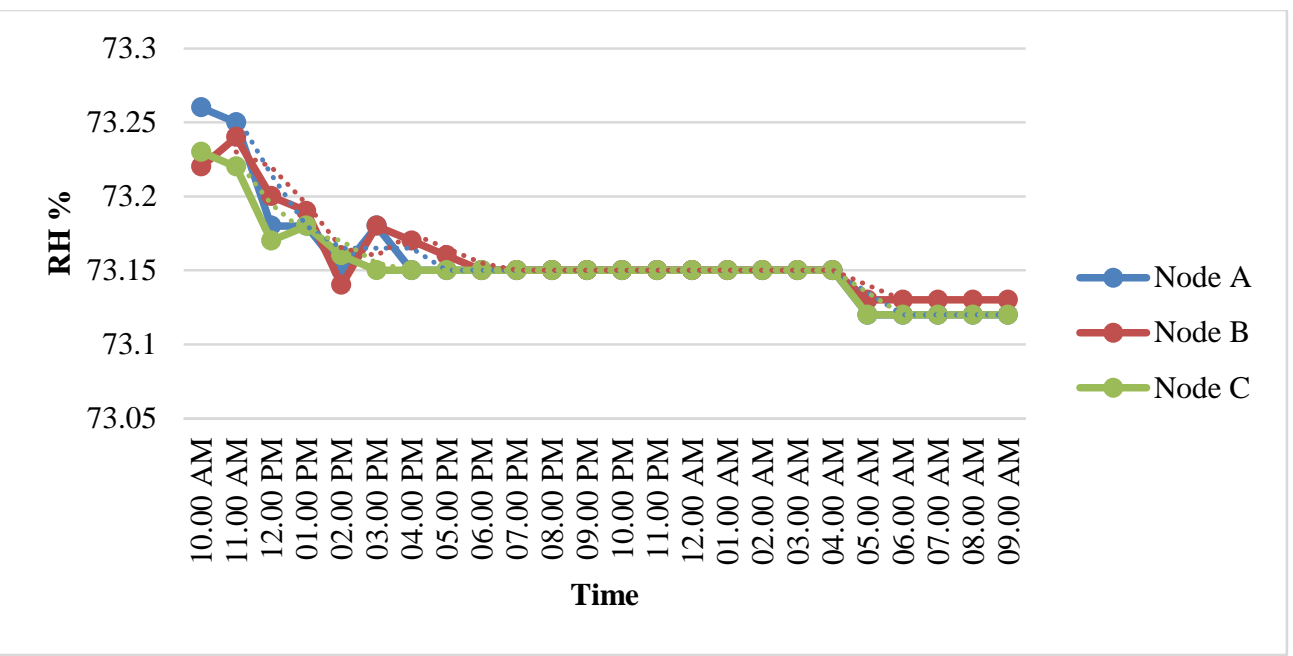

Figure 8 Variation of humidity in laboratory environment

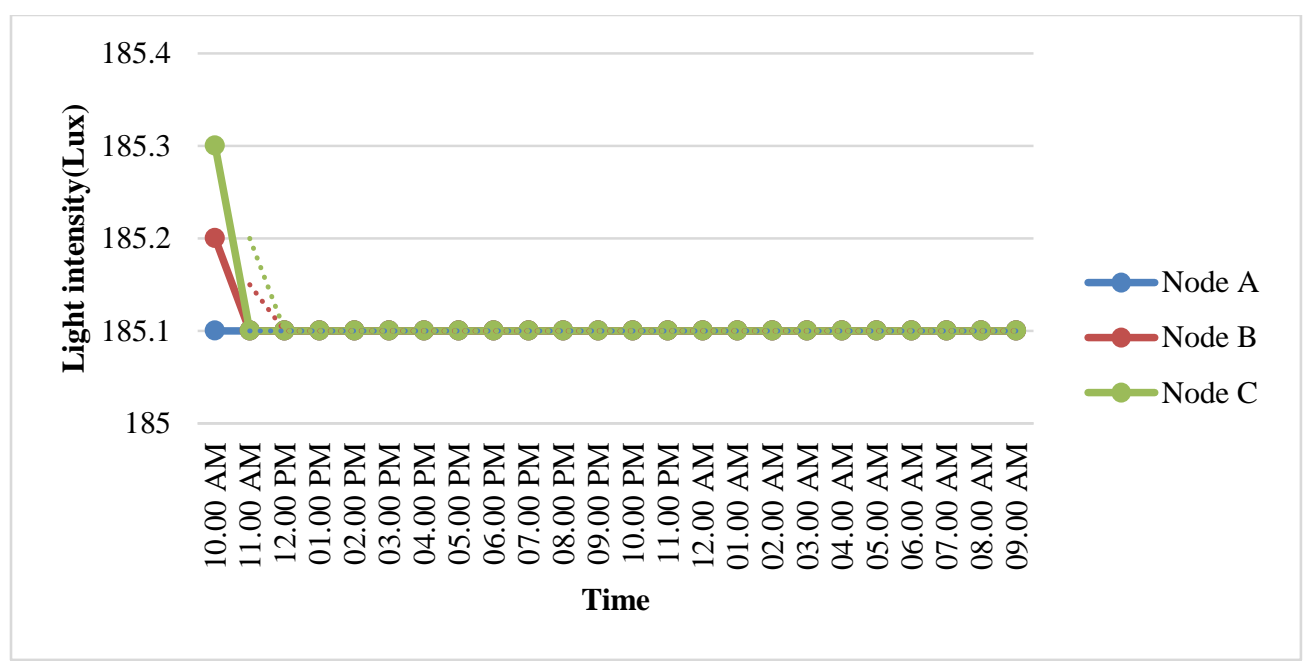

Figure 9 Variation of light intensity in laboratory environment

Maximum average temperature, light intensity and relative humidity obtained in the actual rearing process are $30.2^{\circ} \mathrm{C}, 274 \mathrm{Lux}$ and $89 \%$ respectively. Similarly, minimum average temperature, light intensity and relative humidity obtained in the actual rearing process are $25^{\circ} \mathrm{C}, 58.5 \mathrm{Lux}$ and $66 \%$ respectively.

\section{Field installation}

The developed system has been installed in the rearing room of Assam Agricultural University, Jorhat. It is situated $360 \mathrm{~km}$ east of the testing laboratory. The dimension of the room is $16 \mathrm{ft} \times 24 \mathrm{ft}$ $\times 10 \mathrm{ft}$. The pictorial representation of the rearing room is shown in Figure 10. During the rearing process, the developed system measured and monitored temperature, relative humidity, atmospheric pressure and light intensity in real time. The daily average of acquired data during the rearing period from $29^{\text {th }}$ April 2017 to $29^{\text {th }}$ May 2017 is given in Table 3 and Figure11, Figure 12, Figure 13 represents a variation of rearing room parameters for the day of $1^{\text {st }}$ May, 2017. 


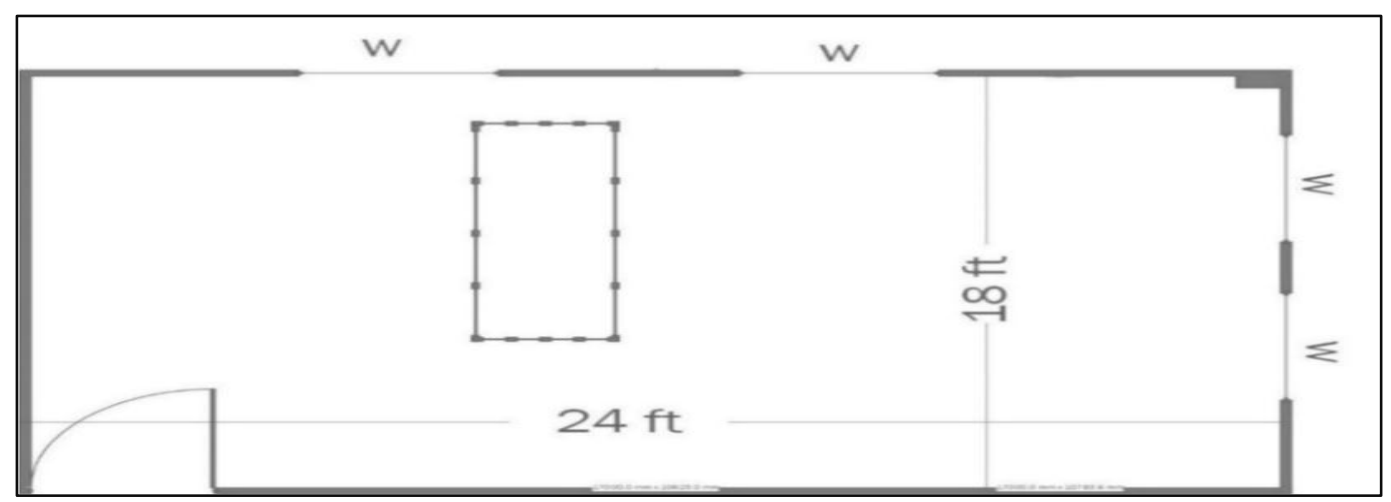

Figure 10 Pictorial view of rearing room

Table 3 Daily average of acquired data

\begin{tabular}{|c|c|c|c|c|c|c|c|c|c|}
\hline \multirow{2}{*}{ Date } & \multicolumn{3}{|c|}{ Temperature $\left({ }^{0} \mathrm{C}\right)$} & \multicolumn{3}{|c|}{ Light intensity (Lux) } & \multicolumn{3}{|c|}{ Relative humidity (\%)) } \\
\hline & $\mathbf{A}$ & B & $\mathbf{C}$ & $\mathbf{A}$ & B & $\mathbf{C}$ & $\mathbf{A}$ & B & $\mathbf{C}$ \\
\hline $29-04-17$ & 26 & 27 & 26.39 & 157.6 & 177 & 173.1 & 71.59 & 70 & 67 \\
\hline $30-04-17$ & 25.77 & 26.51 & 25.83 & 122.5 & 133.8 & 136.9 & 74.87 & 73.84 & 70.99 \\
\hline $01-05-17$ & 25.86 & 26.29 & 25.93 & 129.9 & 139 & 138.4 & 78.01 & 76.56 & 73.42 \\
\hline $02-05-17$ & 26.04 & 26.67 & 26.07 & 153.1 & 166.2 & 161 & 77.73 & 76.33 & 73.19 \\
\hline $03-05-17$ & 26.8 & 26.9 & 26.81 & 114.6 & 120.9 & 109.2 & 69.83 & 68.99 & 67.1 \\
\hline 04-05-17 & 25.82 & 25.13 & 25.75 & 112.7 & 129.7 & 121.6 & 71.66 & 70.98 & 69.39 \\
\hline $05-05-17$ & 25.65 & 25.76 & 25.65 & 58.56 & 68.13 & 69.53 & 79.32 & 78.31 & 74.67 \\
\hline $06-05-17$ & 25.78 & 25.91 & 25.86 & 202.1 & 230.3 & 226.2 & 75.06 & 73.66 & 70.14 \\
\hline $07-05-17$ & 26.33 & 27.11 & 27 & 178.2 & 163.9 & 188.1 & 78.13 & 77.12 & 77.88 \\
\hline 08-05-17 & 27.77 & 28.09 & 27.75 & 158.5 & 166.5 & 159.4 & 81.41 & 80.15 & 76.99 \\
\hline 09-05-17 & 28.53 & 28.81 & 28.2 & 125.4 & 134.7 & 120.1 & 77.65 & 76.44 & 73.79 \\
\hline $10-05-17$ & 26 & 26.47 & 26 & 264 & 269 & 274 & 87 & 86.7 & 85 \\
\hline $11-05-17$ & 26.42 & 27 & 26.42 & 136.1 & 143.7 & 141.5 & 87.83 & 89 & 85 \\
\hline $12-05-17$ & 28.77 & 28.86 & 28.69 & 233.1 & 242.2 & 244.7 & 76.42 & 75.11 & 72.54 \\
\hline $13-05-17$ & 29.14 & 29.61 & 28.95 & 137.4 & 143.5 & 157 & 81.44 & 80.05 & 77.17 \\
\hline $14-05-17$ & 27 & 27 & 27 & 148.7 & 158.3 & 131.1 & 83.07 & 83 & 80 \\
\hline $15-05-17$ & 28.98 & 29.86 & 28.96 & 102.1 & 107.9 & 109.3 & 79.27 & 77.89 & 75.26 \\
\hline $16-05-17$ & 28.58 & 28.95 & 27.93 & 69.79 & 64.69 & 62.24 & 77.36 & 75.87 & 74.41 \\
\hline $17-05-17$ & 28.93 & 28.99 & 28.86 & 132 & 134.3 & 125.3 & 73.78 & 72.61 & 70.08 \\
\hline $18-05-17$ & 29.98 & 30.2 & 29.95 & 110.4 & 135.1 & 144.2 & 69.55 & 68.55 & 65.975 \\
\hline $19-05-17$ & 28.98 & 28.99 & 28.97 & 158.6 & 200.6 & 198 & 83.11 & 82.27 & 78.22 \\
\hline $20-05-17$ & 28 & 28.96 & 28 & 141.7 & 154.4 & 133.8 & 81.04 & 79.1 & 76.08 \\
\hline $21-05-17$ & 28.58 & 28.81 & 28.62 & 144.7 & 160.1 & 123.8 & 81.36 & 79.16 & 76.62 \\
\hline $22-05-17$ & 28.96 & 28.99 & 28.94 & 138.1 & 160 & 140.6 & 80.21 & 78.16 & 75.4 \\
\hline $23-05-17$ & 27.53 & 28.52 & 28.45 & 145.2 & 152.1 & 145.7 & 76.07 & 76.85 & 68.51 \\
\hline $24-05-17$ & 27.83 & 28.26 & 27.83 & 85.78 & 102.3 & 112.9 & 87.6 & 87.8 & 82.03 \\
\hline $25-05-17$ & 26.97 & 27.51 & 26.99 & 141.7 & 154.4 & 133.8 & 84.23 & 83.42 & 78.98 \\
\hline $26-05-17$ & 27.94 & 28.78 & 28 & 167.2 & 177.1 & 185.7 & 81.07 & 78.85 & 68.51 \\
\hline $27-05-17$ & 28.98 & 29.12 & 29.32 & 139.6 & 161.2 & 141.6 & 81.24 & 80.18 & 80.94 \\
\hline $28-05-17$ & 28.25 & 28.56 & 28.46 & 135.1 & 140.2 & 125.3 & 72.7 & 70.5 & 74.12 \\
\hline $29-05-17$ & 28.35 & 28.42 & 28.3 & 136.7 & 147.1 & 123.1 & 78.3 & 75.1 & 74.12 \\
\hline
\end{tabular}


Arnob Doloi et al.

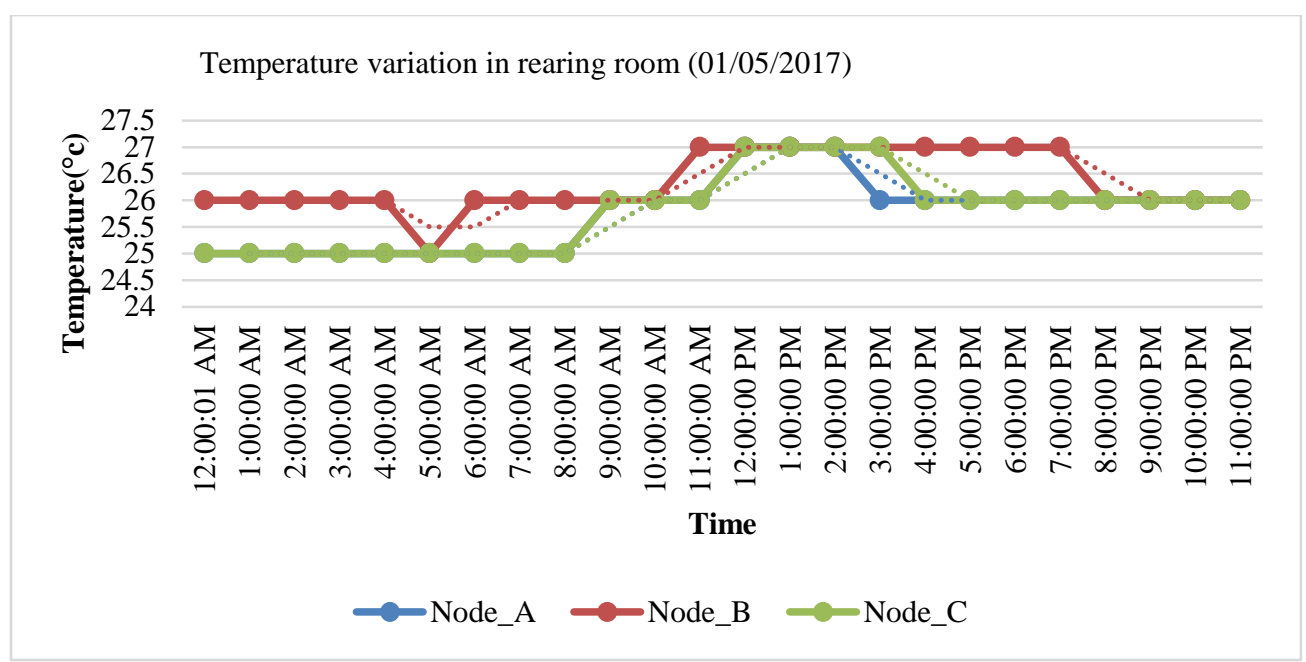

Figure 11 Variation of rearing room temperature date-01/05/2017

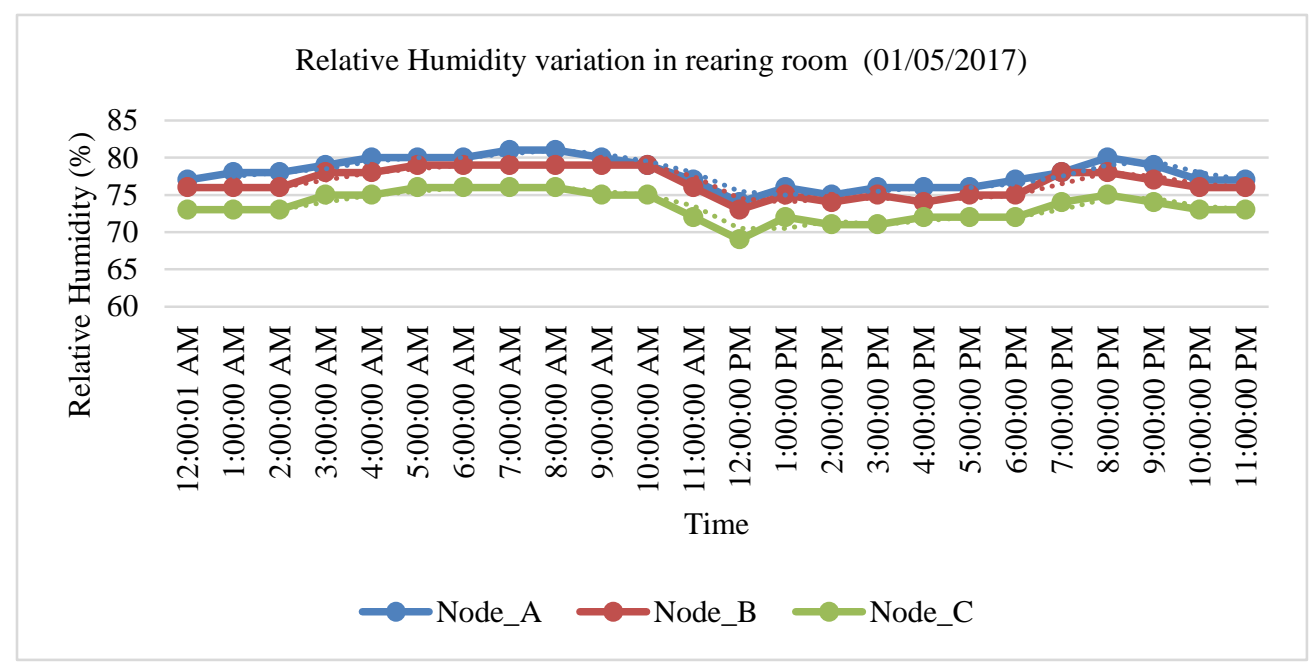

Figure 12 Variation of rearing room relative humidity date-01/05/2017

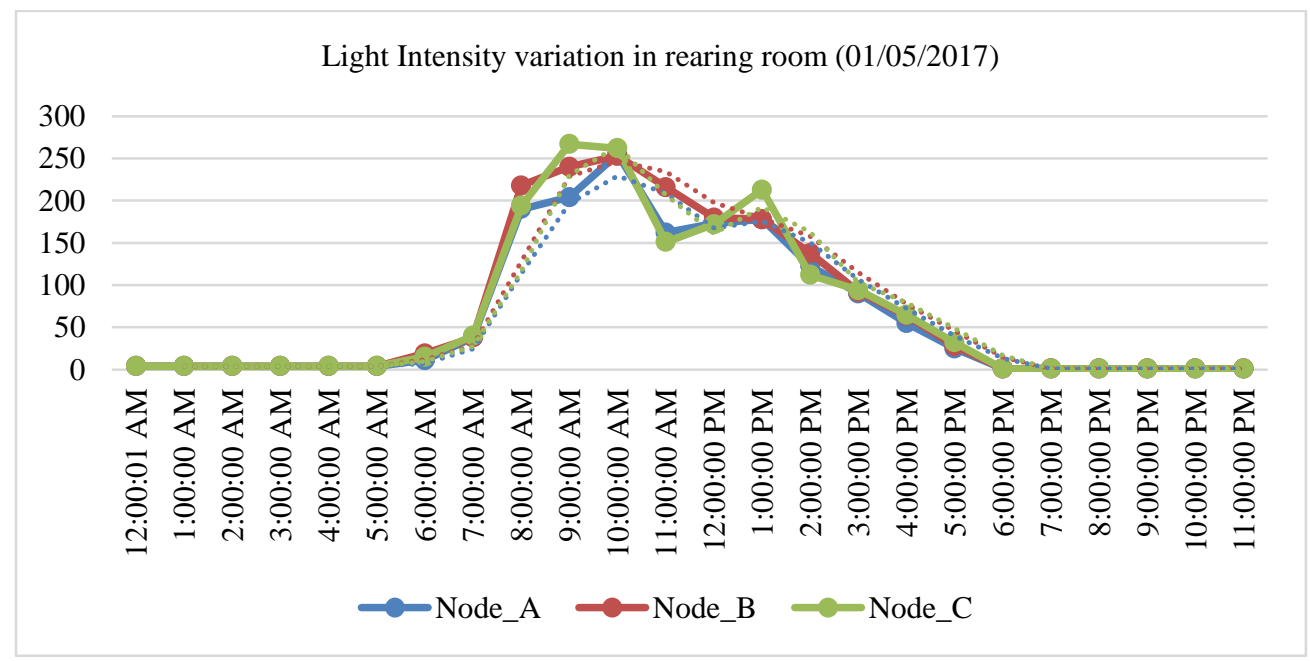

Figure 13 Variation of rearing room light intensity date-01/05/2017 


\section{Conclusion}

The developed system is tested in the laboratory as well as it is installed in the actual rearing process of eri silkworm. It is found to be satisfactory. The instrument is suitable for measuring environmental parameters during the rearing process of the eri silkworm and the optimum parameters can be found out in the process with some extended work. Several advantages of the developed instrument are listed below-

- Low cost

- Low power consumption

- Wireless monitoring of environmental parameters

- Data logging features

- Easy to install

- Plug and play

An IoT based instrument to monitor data globally will further be developed which will helpful for both farmer as well as their scientific advisor for real time system monitoring remotely. Also, GSM/LTE based control and monitoring system can also be implemented.

\section{Acknowledgment}

The Assam Science Technology \& Environment Council (ASTEC) is acknowledged for providing financial support to one of the authors. The authors of the paper acknowledge the authority of Assam Agricultural University for their help and support. The authors acknowledge the supports from Dr. Utpal Sarma, Professor \& HoD, Department of Instrumentation \& USIC, Gauhati University. Dr. Kumud Ghosh is also acknowledged for his help and support.

\section{Conflicts of interest}

The authors have no conflicts of interest to declare.

\section{References}

[1] Hajare TN, Jadhav AD, Venugopalan M, Patil NG, Chaturvedi A, Maji AK. Evaluation of sericulture for augmenting agricultural income of marginal farmers in semi-arid region of India. International conference "sericulture challenges in the 21st century. 2007(p. 294).

[2] http://csb.gov.in/publications/annual-report/. Accessed 6 January 2019.

[3] https://des.assam.gov.in/informationservices/economic-survey-assam. Accessed 6 January 2019.

[4] Reddy DN, Gowda M, Narayanaswamy KC. Ericulture: an insight. Zen Pubulication, Bangalore, India. 2002.

[5] Ghosh CC. Silk production and weaving in India. Council of Scientific and Industrial Research; 1949.
[6] Fukuda T, Higuchi Y, Matsuda M. Artificial food for eri-silkworm raising. Agricultural and Biological Chemistry. 1961; 25(5):417-20.

[7] Jolly MS, Chowdhury SN, Sen SK. Non-mulberry sericulture in India. Central Silk Board; 1975.

[8] https://sericulture.assam.gov.in/ . Accessed 6 January 2019.

[9] http://silkwormmori.blogspot.com/2009/09/indiansericulture-optimists-review-dr.html. Accessed 27 February 2019.

[10] Legay JM. Recent advances in silkworm nutrition. Annual Review of Entomology. 1958; 3:75-86.

[11] Krishnaswamy S. Silkworm feeding traits for evaluating the quality of mulberry leaves as influenced by variety, spacing and nitrogen fertilization. Indian Journal of Sericulture. 1971; 9(1):79-89.

[12] Krishnaswami S. New technology of silkworm rearing. II. Indian Silk. 1978.

[13] Yadav GS, Mahobia GP. Effect of different food leaves on rearing performance in Indian tropical tasar silkworm, Antheraea mylitta Drury (Lepidoptera: Saturniidae). Uttar Pradesh Journal of Zoology. 2010; 30(2):145-52.

[14] Sugai E, Takahashi T. High temperature environment at the spinning stage and sterilization in the males of the silkworm, Bombyx mori. The Journal of Sericultural Science of Japan. 1981; 50(1):65-9.

[15] Sahu M, Bhuyan N, Das PK. Eri silkworm, Samia ricini (Lepidoptera: Saturniidae) Donovan, seed production during summer in Assam. In proceeding of regional seminar on prospects and problems of sericulture as an economic enterprise in North West India 2006 (pp. 11-2).

[16] https://www.abebooks.com/ERI-Culture-R.N-SinghAPH-Publishing/21328312369/bd. Accessed 6 January 2019.

[17] Sadowski S, Spachos P. Solar-powered smart agricultural monitoring system using internet of things devices. In annual information technology, electronics and mobile communication conference 2018 (pp. 1823). IEEE.

[18] Khan WZ, Aalsalem MY, Khan MK, Hossain MS, Atiquzzaman M. A reliable internet of things based architecture for oil and gas industry. In international conference on advanced communication technology 2017 (pp. 705-10). IEEE.

[19] https://www.boschsensortec.com/bst/products/all_products/bme280. Accessed 6 January 2019.

[20] https://www.mouser.in/datasheet/2/348/Rohm_111620 17_ROHMS34826-1-1279292.pdf. Accessed 6 January 2019.

[21] http://www.alldatasheet.com/view.jsp?Searchword=At mega328p\&gclid=CjwKCAjwm- fkBRBBEiwA966 f ZC71 qDR4TKGe8WyIpodFPfgCP-Rxy7QAegyhu3 Zax UA qH_C6y-dL6RoC25AQAvD_BwE. Accessed 6 January 2019

[22] http://www.alldatasheet.com/view.jsp?Searchword=C c2500\%20datasheet\&gclid=CjwKCAjwm-fkBRBBE iwA966fZBDq3oeApQfnkS2iWaYv0di62cvuEebRQx 
Arnob Doloi et al.

x9741k2cMTavO_6Uh7EBoCIb8QAvD_BwE. Accessed 6 January 2019.

[23] Roberts LG, Wessler BD. Computer network development to achieve resource sharing. In AFIPS spring joint computing conference 1970 (pp. 543-9).

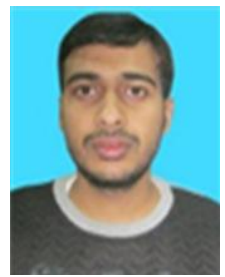

Arnob Doloi completed his masters on Instrumentation \& Applied Physics from Gauhati University, Jalukbari, Guwahati, Assam, India. $\mathrm{He}$ is interested in Embedded System and Sericulture.

Email: arnobdoloi@gmail.com

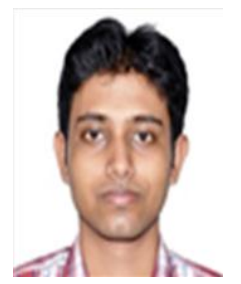

Nairit Barkataki received his M.Sc. degree from Gauhati University, Jalukbari, Guwahati, Assam, India. Currently he is an Assistant Professor at Gauhati University. His research interests are Microwave Imaging and Non-Destructive Testing,

Dielectric Materials, Instrumentation for Sericulture and Radar Signal Processing.

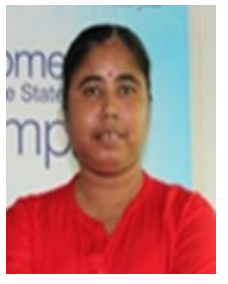

Dr. Monimala Saikia is serving as Assistant Professor of Sericulture, Assam Agricultural University, Jorhat since 2016. She has also served as Assistant Professor in College of Sericulture, AAU, Jorhat. Dr. Saikia published around twenty research papers in highly impacted journals and proceedings of the conference. Her area of interest is wild silkmoths. She is a recognized guide for Masters in Agriculture.

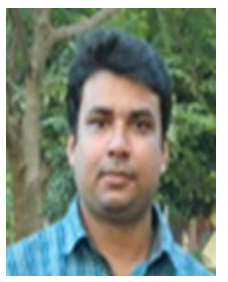

Dr. Debashis Saikia Completed his Ph.D from Gauhati University under the faculty of technology. $\mathrm{He}$ is currently working as an Assistant Professor in the Department of Instrumentation and USIC, Gauhati University. His research interests are Smart Sensor, Instrumentation for Tea Process and Sericulture, Soft Computing and Sensor Network. 